\title{
Kronik Böbrek Hastalıkları ile Diyaliz Birimlerinde Hemşirelerin Maliyet-Etkililik ve Verimliliğe Etkisi
}

\author{
Impact of Nurses to Cost-Effectivity and \\ Productivity in Chronic Kidney Disease \\ and Dialysis Units
}

\section{Nurcan BíLGiç}

Yrd. Doç. Dr. Lefke Avrupa Üniversitesi Hemşirelik Yüksekokulu. Lefke, KKTC

Geliş Tarihi: 23 Temmuz 2019

Kabul Tarihi: 25 Ekim 2019

İletişim / Correspondence:

Nurcan BİLGíç

E-posta: nurcan.bilgic@gmail.com

\section{Özet}

Dünyada ve ülkemizde salgın halinde görülen Kronik Böbrek Hastalığı $(\mathrm{KBH})$ önemli bir halk sağlığı sorunudur. KBH global mortalite nedenleri arasında hızlı bir şekilde artmaktadır. Dünyada yaklaşık 2 milyon hasta diyaliz ve böbrek nakli tedavileri ile yaşamını sürdürmekte, 2020 yılında diyaliz tedavisine ihtiyaç duyması beklenen kişi sayısının 3.5 milyon dolayında olacağı öngürülmektedir. $\mathrm{KBH}$ ve böbrek yetmezliklerinin son dönemlerinde sağlık maliyetleri hem kişilerin hem de ülkelerin sağlığa ayırdığı maliyetleri oldukça olumsuz yönde etkilemektedir. Hemşireler, tüm hastaların zarar görmesini engelleyecek şekilde hasta güvenliğini sağlamakta, verdiği tüm hizmet süreçlerinde adil olmaya dikkat etmekte, hastalara uygun hizmet sağlamada hasta odaklı çalışmakta, hastalara bakım sırasında uygun bakımı ve süreçleri yönetmekte, hastalara bakımı zamanında ve sürekli olarak vermektedir. Hemşireler diyaliz hastalarına bakım verirken North American Nursing Diagnosıs Assocation (NANDA), hemşirelik girişimlerinin standardize edilmiş bir sınıflandırmasını kullanmaktadırlar. Sağlık kurumlarında çalışan hemşireler, kurumların verimliliğinin artmasında önemli bir işgücüne sahiptir. Hemşirelerin motivasyonunun artırılmasının sağlanması, verimlilik ile birlikte hasta ve hasta yakınlarının da memnuniyetini artıracaktır. Kurumlar sağlık alanda kalıcılık sağlamak istiyorsa, hemşirelerin işgücü verimliliğini artıracak hedefleri planlamalı, uygulamalı, gerektiği alanlarda iyileştirmeler yapmalıdır. Diyalizde hemşirelik mezunu ve bu konuda sertifika sahibi olanların çalıştırılması maliyet-etkililik açısından önemlidir.

Anahtar Kelimeler: Kronik Böbrek Hastalığı, Diyaliz Hemşireliği, Maliyet-Etkililik.

\begin{abstract}
Chronic Kidney Disease (CKD), seen as contagious in our country and in the world, is a crucial public health problem. CKD is rapidly increasing among the global mortality causes. Approximately 2 million patients have been maintaining their lives with dialysis and kidney transplant treatments, and it is predicted that the number of people who are expected to need dialysis treatment will be around 3.5 million in 2020. Recent health costs of CKD and kidney failure affects the health costs of both people and countries in a negative way. Nurses provide the patient safety in a way to prevent harm to all patients, pay attention to the equity
\end{abstract}


in all service processes they give, work as patient-focused to provide appropriate service to the patients, manage the appropriate care and process during the patient care, and give care to the patients timely and consistently. Nurses use a standardized classification of nursing initiatives, North American Nursing Diagnosis Association (NANDA) while giving care to the dialysis patients. Nurses who are working in health institutions have a crucial labor force in increasing the institution productivity. Providing the motivation increase of nurses increases the satisfaction of patient and patient's relatives in addition with the productivity. If the institutions hope to provide a persistency in the fields of health, they need to plan and apply the goals that will increase the labor force productivity of nurses, and make improvements in necessary fields. It is important to employ people with bachelor of nursing and certificate holder about this subject in terms of cost-effectivity.

Keywords: Chronic Kidney Disease; Dialysis Nursing; Cost-Effectivity.

\section{GİRIŞ}

\section{Kronik Böbrek Hastalığı ve Son Dönem Böbrek Yetmezliğine Genel Bakış}

Primer koruma kapsamında yapılan çalışmaların artırılması ile; hastaların erken saptanması istenmektedir (1-3). Kronik Böbrek Hastalığı (KBH) sıklıkla önlenebilir veya ilerlemesi geciktirilebilir bir durum olmasına karşın, hastalığın bireyler tarafından farkındalık düzeyinin düşük olması ve buna bağlı olarak erken tanıda geç kalınması gibi nedenlerle her y1l artmaktadır $(4,5)$. Dünya nüfusunun yaklaşık \%10'u kronik böbrek hastalıklarindan etkilenmektedir. KBH global mortalite nedenleri arasında hızlı bir şekilde artmakta ve son yillarda 3. sırada yer almaktadır. Halen tüm dünyada yaklaşık 2 milyon hasta diyaliz ve böbrek transplantasyon tedavileri ile yaşamını sürdürmeye çalışmaktadır (5). Yapılan araştırmalarda; 2020 yılında diyaliz tedavisine ihtiyaç duyması beklenen kişi sayısının 3.5 milyon dolayında olacağı öngörülmektedir $(6,7)$.

Kronik Böbrek Hastalıkları ve böbrek yetmezliklerinin son dönemlerinde sağlık maliyetleri hem bireylerin, hem de ülkelerin sağlığa ayırdığı maliyetleri olumsuz yönde etkilemektedir $(7,8)$. Dünya Böbrek Günü kapsamında yayınlanan raporda (2017); Birleşmiş Milletler'in sağlik bakım programlarında son dönem böbrek yetmezliğinin yıllık maliyetinin ülke ekonomisine 35 milyar dolar yük getirdiği belirtilmektedir (8). Koruyucu hizmetlerde yeterli düzeye ulaşılamaması, hasta sayısının her geçen yıl artması, tedavinin yapıldığı merkez ve bu merkezlerde yapılan uygulama maliyetlerinin artması ile önümüzdeki birkaç yıl içerisinde gelişmiş ülkelerin sağlık bütçelerinin ciddi olarak zorlanacağ 1 , daha düşük gelir düzeyine sahip ülkelerde ise altından kalk1lmas1 mümkün olmayan bir ekonomik yükün ortaya çıkacağı belirtilmektedir $(8,9)$.

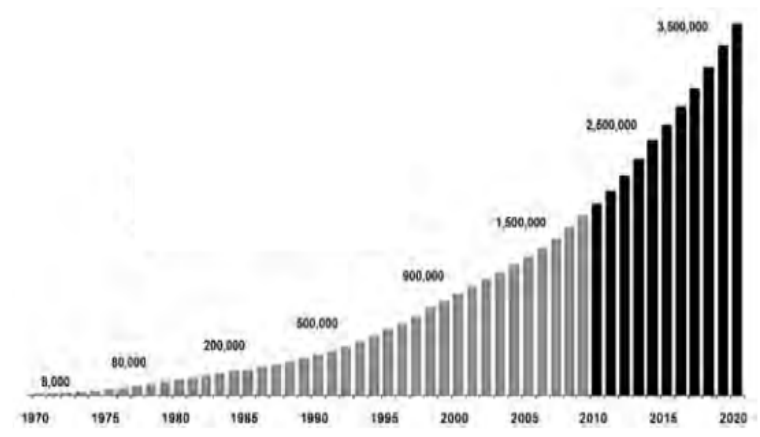

Şekil 1. Dünya'da diyaliz hastası sayısının artışı

References: Kasti J, Pancirova, Dialysis Enviromental Guide, A Practical Guide to Reducing The Enviromental Burden of Dailysis, European Dialysis and Transplant Nurses Association/ European Renal Care Association (EDTNA/ERCA), Imprenta Tomás Hermanos Río Manzanares, 42-44 E28970 Humanes de Madrid Madrid - Spain, English Edition September 2011, Turkish Edition May 2013.

Böbrek yetmezliği ve KBH'nın son evresinde olan hastaların büyük bir kısmı düşük ve orta gelir düzeyindeki ülkelerde yaşamakta olup, mortalite oranı gelişmiş ülkelerde yaşayan hastalara göre daha yüksektir $(10,11)$. 
Ülkemizdeki genel yetişkin popülasyonda $\mathrm{KBH}$ sıklığ $\%$ 17,6'dır ve toplumdaki her 6 -7 kişiden biri KBH'dan etkilenmektedir $(1,2,7)$. Türk Nefroloji Derneği tarafından periyodik olarak elde edilen Ulusal Böbrek Kayıt Sistemi verilerine göre, Son Dönem Böbrek Yetmezliği (SDBY) prevalansı ülkemizde de hızlı bir biçimde artmaktadır. Türkiye'de 2001 yllında milyon nüfus başına 314 olan SDBY'li hasta sayıs1, geçen on y1llık sürede 2,5 kattan fazla artarak milyon nüfus başına 800'ü aşmıştır (12). Sağlık Bakanlığı'nın (SB) 2016 yılında açıkladığı verilere göre, Türkiye'deki kamu ve özel diyaliz merkezlerinde tedavi gören hasta sayıs1 60.573'tür. Sağl1k Bakanlığ Kan, Organ ve Doku Nakil Hizmetleri Daire Başkanlığı'nın Mayıs 2019 itibariyle açıkladığı verilerde; 2018 yılında 3.874, 2019 yılı ilk 4 ayında 1.334 hastaya böbrek transplantasyonu yapılmıştır (13). Bu hastalara uygulanan tedavinin maliyeti ise ülkemizde sağlığa ayrılan bütçenin \% 5 'inden fazlasına denk gelmektedir.

Kidney Disease Improving Global Outcomes (KDIGO-2017) Klinik Uygulama Kılavuzuna göre kronik böbrek hastalığı tanısı konulabilmesi için; üç ay veya daha uzun süren böbrek hasar1nın olması (Glomerüler Filtrasyon Hızı [GFH] değişiklikleri), patolojik (yapısal) anormalliklerin olması, idrarda (proteinüri varlığı vb), kanda (renal tübüler sendromların varlığı) ya da görüntüleme yöntemlerinde saptanan anormallikler ile böbrek transplantasyonu ve/ veya üç ay veya daha uzun süren GFH azalması olmas1 gereklidir (11).

Kronik böbrek hastalığı olan bireylerde, hastalığın erken evrelerinden itibaren kardiyovasküler nedenlere bağlı olarak morbidite ve mortalite riskleri artmaktadır. Amerika Birleşik Devletleri'nde yapılan kapsamlı ve toplum temelli bir çalışmada, KBH'li bir hastanin mortalite riskinin SDBY'ye ilerleme olasılığından 16 kat yüksek olduğu belirlenmiştir (14). Zaman içinde diyalize başlayan hastaların ise yarıya yakını 5 yıl içinde hayatını kaybetmektedir (15). Hastalara böbrek transplantasyonu yapılması ile kişilerin yaşam süreleri anlamlı olarak artmasına rağmen, tam bir iyilik hali hiçbir zaman olmamaktadır. Yüksek morbidite oranları ve kötü yaşam kalitesi hastaların ve ailelerinin hem sosyal yaşantılarını hem de ekonomik üretkenliklerini olumsuz etkilemekte ve bunun sonucunda da hastalığın ülke düzeyinde yarattığı ekonomik kayıplar daha da artırmaktadır (16).

Ülkemizde tüm yaş grupları arasında erkekler kadınlara göre daha fazla diyaliz tedavisi almaktadır. Ayrıca diyalize giren hastaların etiyolojileri incelendiğinde, hastaların \% 35'inde diabetes mellitus, \%28'inde kardiyovasküler hastalıkların olduğu ve hastaların bu etiyolojiler nedeni ile yaşamlarını kaybettiği bildirilmektedir $(7,17)$.

\section{Diyaliz Nedir ve Nerelerde Uygulanır?}

Hemodiyaliz, böbrek hastalarının kanında bulunan üremik maddeleri filtrelemek için ekstrakorporal bir kan arındırma işlemi olarak tanımlanmaktadır. Arındırma işlemi yarı geçirgen membranların kullanılması ile yapılmaktadır. Thomas Graham tarafindan ilk kez 1854 yılinda tanımlanmış ve bunun için düzenek oluşturularak işlem yapılmış ve işlem sonrasında düzenekte arta kalanlar idrarın içindeki maddeler olmuştur. İslevsel bir hemodiyaliz aletinin Kolodyon membranlarının kullanımı ile Abel ve ark. tarafindan 1914 yılında ilk işlevsel diyaliz işlemi köpekler üzerinde uygulanmıştır. İnsanlar üzerindeki ilk diyaliz tedavisi ise 1924 yılında Georg Haas tarafindan gerçekleştirmiştir. 1943 yılında Willem Kolff tarafindan selofan membranlarının ve immersiyon banyosunun kullanıldığ 1 dönen varilli hemodiyaliz sistemi uygulanmaya başlanmıştır. Bu yöntemle akut böbrek yetmezliği olan bir hasta bir hafta süreyle tedavi edilmiş ve bu hasta hemodiyaliz tedavisi ile tamamen iyileşen ilk hasta olmuştur. Bu tedavi yapay renal replasman terapisinin de başlangıcı kabul edilmektedir. Kiil tarafından 1960 yılında geliştirilen değiştirilebilir plakalı diyaliz cihazı geleneksel Kolff böbreğine göre diyaliz ve ultrafiltrasyon işlemlerini daha iyi birleştirmektedir. Uzmanlar tedavilerin kalitesini arttırmak, morbidite ve mortalite oranlarını düşürmek için çalışmalara devam etmektedir $(6,18)$.

Halen SDBY hastaları haftada üç defa geleneksel hemodiyaliz tedavisi almaktadır. Günümüzde ayrica daha uzun süren veya daha sik alınan diyaliz, noktürnal hemodiyaliz, günlük kısa hemodiyaliz, evde hemodiyaliz ve hemodiyafiltrasyon gibi alternatif hemodiyaliz uygulamalarının yanı sıra son yıllarda yüksek akışlı diyaliz cihazı kullanımı artmaktadır (6). 
Evde uygulanabilen hemodiyaliz tedavisi, altyapısal ve işgücü bakımından merkezlerde yapılan hemodiyalize kıyasla ekonomik açıdan daha uygun ve sürdürülebilir niteliktedir. Kamu kurumlarında ve merkezlerde işgücü giderlerinin fazla olması, hemşire sayısının kısıtlılığı, son günlerde diyaliz hemşirelerinin görev ve yetkilerinin elinden alınarak merkezlerden çıkartılması ve yerlerine iki yıllık meslek yüksekokulu mezunu teknikerlerin yerleştirilmesi, daha fazla hasta tedavisinin sağlanabilmesi için yeterli fiziksel alanın bulunmaması, diyaliz sağlayıcılarının artan maddi yükleri evde uygulanan hemodiyaliz seçeneğinin daha fazla gündeme gelmesine neden olmaktadır. Evde hemşire gözetiminde yapılan hemodiyalizlerde hastalar ve aileler sosyal ve psikolojik açıdan daha uyumlu olmaktadır. Evde yapılan diyalizlerle ilgili gözleme dayalı çalışmalarda, beklenen morbidite oranlarının düştüğü ifade edilmektedir. Hemşireler tarafindan eğitimlerinin sürekli yapılması ve hemşirelik girişimleri sonucunda hastaların daha az ilaç kullandığı, sağlık ve bakım masraflarının azaldığ 1 ve hastaneye yatma sıklığındaki düşüş gibi faktörler evde yapılan diyaliz uygulanmasının tercih edilirliğini artıracaktır $(8,9)$.

\section{Sağlık Kurumlarında İşgücü Verimliliği ve Maliyet Etkililiğinde Hemşirenin Rolü}

Sağlık kuruluşlarda sunulan diyaliz hizmetlerinin hedeflerine ulaşabilmesi için organizasyonel ve kurumdan hizmet alanları birebir ilgilendiren hedeflerin belirlenmiş olması gereklidir. Organizasyonel hedefler kurumun hizmet sunum şeklidir ve bu kapsamda etkililik, etkinlik, verimlilik ve sağlıklı çalışma yaşamı oluşturulması hedeflenir. Kurumdan hizmet alanları birebir ilgilendiren hedefler ise hasta güvenliği, adil olma, hasta odaklılık, uygunluk, zamanlılık ve sürekliliktir (4). Organizasyonel hedeflerin sunumu sirasında; etkinlik aşamasında planlanan hedeflere ulaşmak, bu etkinliklerde bireylerin işleri doğru yapabilme kabiliyetlerine sahip olmasını sağlamak, verimlilikte ise üretilen hizmetler ile bu hizmetlerin üretilmesinde kullanılan girdiler arasındaki ilişkinin en az kaynak kullanarak hedeflere ulaşı1masını sağlamak amaçlanmalıdır. Tüm bunların sağlıklı bir çalışma ortamında gerçekleşmesi hemşirelerin motivasyonunu da artıracaktır. Ayrıca hemşireler, tüm hastaların zarar görmesini önleyecek şekilde hasta güvenliğini sağlamakta, verdiği tüm hizmet süreçlerinde adil olmaya dikkat etmekte, hastalara uygun hizmet sağlamada hasta odaklı çalışmakta, hastalara bakım sırasında uygun bakımı ve süreçleri yönetmekte, hastalara bakımı zamanında ve sürekli olarak vermektedir. Tüm bunları yaparken "Hemşireler İçin Etik İlke ve Sorumlulukları"na dikkat etmektedir $(4,20)$.

Son yıllarda hizmet sektöründe işgücü verimliliğinin önemi daha fazla öne çıkmakta ve bu konuda iyileştirme, geliştirme çalışmaları giderek artmaktadır. Sağlık sektörü de bu gelişmelerden olumlu olarak etkilenmektedir. İşgücü verimliliği, çalışanların yapmakta oldukları işlerdeki başarı oranlarının artması olarak tanımlanmaktadır. Çalışanların motivasyonunun sağlanması işgücü verimliliğini artırmakta, bu da kurumların başarısını doğrudan etkilemektedir $(1,3,8,9)$.

Sağlik kurumunda üretilen hizmet genel olarak insan gücüne dayalıdır. Sağlık kurumlarında motivasyonu yüksek ve çalışmaya hevesli kişilerin yaptıkları işlerde daha başarılı olduğu gözlemlenmektedir. $\mathrm{Bu}$ da sağlık kurumlarında verimliliğin artmasında en önemli etken olan işgücünün önemini ortaya koymaktadır. Sağlık kurumlarında çalışan hemşireler, kurumların verimliliğinin artmasında önemli bir işgücüne sahiptir. Hemşirelerin motivasyonunun artırılmas1 hem verimlilik hem de hasta ve hasta yakınlarının memnuniyetini artıracaktır. Kurumlar bulundukları alanda kalıcılık sağlamak istiyorsa, vizyon ve misyonları doğrultusunda hemşirelerin işgücü verimliliğini artıracak hedefleri planlamalı, uygulamalı, gerektiği alanlarda iyileştirmeler yapmalıdır.

Ülkemizde diyaliz hemşirelerinin görev, yetki ve sorumlulukları, Sağlık Bakanlığı'nın 19 Nisan 2011 tarihli Hemşirelik Yönetmeliği'nde Değişiklik Yapılmasına Dair Yönetmeliği'nde tanımlanmaktadır. Hemşireler genel görev, yetki ve sorumluluklarının yanı sira hastaların kendi kendine yönetimini ve bakımını destekler. Diyaliz işlemi sırasında oluşabilecek komplikasyonlara yönelik girişimlerde bulunur. Hastaya sosyal ve psikolojik destek açısından uygun yönlendirmelerde bulunur. Diyaliz giriş yerinin bakımını yapar. Ayrıca hastaya uygulanan diyaliz tedavisinin etkinliğini artırmak, tedavi maliyet- 
lerinin azaltılmasını sağlamak için hasta ve hasta yakınlarına diyaliz işlemi, diyaliz süresi ve fistül bakımı ile hastanın evdeki bakımına ilişkin eğitim verir. Aynı yönetmelik kapsamında, hemşireler hekim kararı ile hemodiyaliz ve periton diyalizi uygularlar $(21,22)$.

Hemşireler sağlıklı bir toplum oluşturmak için koruyucu bakım kapsamında sağlığın korunması ve geliştirilmesi, sağlık eğitimi gibi birçok görev üstlenmişlerdir. Hemșirelerin özellikle birinci basamakta yapması gereken en önemli koruyucu bakım hizmeti, bireylerin KBH farkındalığını arttırmak olduğu söylenebilir. Dünya genelinde yapılan çalışmalarda, bireylerin sadece \%10'unun KBH'nın farkında olduğu belirlenmiştir (23). Ülkemizde ise farkındalık düzeyi daha da düşüktür. Türk Nefroloji Derneği (TND) tarafindan yapılan Türkiye Kronik Böbrek Hastalığı Prevalans Çalışması'na (CREDIT) göre ülkemizde KBH'nın farkındalık düzeyi \% 2'nin altındadır (13). Bireylerin düşük farkındalıkları sonucu, hastalar SDBY evresine hızla ilerlemekte, hastalarda yüksek morbidite ve mortalite oranları saptanmakta, hastaların yaşam kalitesi düşmektedir. Ayrıca hastalar daha sık ve uzun sürelerle yüksek maliyetli diyaliz uygulamaları ile böbrek transplantasyonu tedavilerine ihtiyaç duymaktadir $(4,17)$.

Diyaliz tedavisi sırasında hemşirelik uygulamalarının kanıta dayalı olması, hastanın tercihlerinin ve değerlerinin göz önüde bulundurulması, kinik uzman deneyimlerinden faydalanılması, hasta bakımı verilerinin ve yapılan çalışmaların sonuçlarının değerlendirilmesi önemlidir. Ayrıca hemşirelerin çalıştıkları kurumların destekleyici örgüt kültürünün olması ve kanıt temelli yaklaşımı benimsemesi durumunda hasta sonuçları daha iyi seviyelere ulaşır, hastalara verilen bakımın kalitesi ve hemşire memnuniyeti de olumlu yönde $\operatorname{artar}(24)$.

North American Nursing Diagnosis Assocation (NANDA), hemşirelik girişimlerinin standardize edilmiş bir sınıflandırmasını Nursing Interventions of Classifications (NIC) ve hemşirelik girişimlerinin sonuçlarının değerlendirilmesinde kullanılmak üzere, beklenen hasta sonuçlarının standardize edilmiş sınıflandırmasını Nursing Outcome Classifications (NOC) kullanarak yapmıştır. KBY olan hastalarda sinıflandırma NANDA tarafından onaylanan, fonksiyonel sağlık örüntülerine göre gruplandırılmış hemşirelik tanılarından oluşturulmuştur. Hemşirelik tanısı olarak sıvı volüm eksikliği, deri bütünlüğünde bozulma, yaralanma riski (kırık vb), aktivite intoleransı, beslenmede değişiklik: beden gereksiniminden az beslenme, konstipasyon, diyare, enfeksiyon riski, düşünce sürecinde değişiklik ve bilgi eksikliği tanımlanmaktadır (25-28). Hemşireler bu tanılara uygun hemşirelik bakım planını yapmakta, hemşirelik girişimlerini uygulamakta ve sonuçları değerlendirerek kayıt altına almaktadırlar.

Türkiye'de KBH'lı bireyler ve diyaliz ünitesinde çalışacak hemşirelerin mesleki gelişimlerinin artırılabilmesi için uzun yıllardır mesleki eğitim üzerine sertifika programları uygulanmaktadır. Sağlık Bakanlığı'nın 1993 yılında yayımladığı Diyaliz Merkezleri Hakkındaki Yönetmelik'e göre; bir diyaliz merkezi ya da ünitesi başına bir nefrolog ya da sertifikalı bir uzman hekim, 20 hemodiyaliz cihazına bir sertifikalı diyaliz hekimi ve her beş hemodiyaliz cihazına bir sertifikalı hemşire ya da sertifikalı ebe ya da sertifikalı sağlık memuru zorunluluğu getirilmiştir. 1998 yılında ebeler sertifika programından çıkarılmış, 2010 yılında çıkarılan yönetmelikte ise diyaliz teknikerliği eklenmiştir (29). 2019 yılında çıkarılan yönetmelikte ise hemodiyaliz ve periton diyalizinin birlikte yapıldığı merkezde, sertifikalı hemşire veya sertifikalı diyaliz teknikeri hem hemodiyaliz hem de periton diyalizi bakımından faaliyet iznine esas personel olarak kabul edilir. Ancak bu durumdaki sertifikalı hemşireler ve sertifikalı diyaliz teknikerleri eş zamanlı mesai yapamaz ibaresi yer almaktadır. Ayrıca eklenen geçici maddede, hemşireler için sertifikalı eğitim programları kaldırılmış olup, bu maddenin yürürlüğe girdiği tarihten önce hemodiyaliz sertifikası almış, geçerli sertifikası olan hemşirelerin tüm hakları saklıdır denmektedir. Bu yönetmelikle beraber diyaliz birimlerinde, hemşirelerin koruyucu, tedavi edici, eğitim ve savunucuk görevlerinin yapabilmesinin önü kapatılmıştır. Hemşirelerin diyaliz merkezlerinde çalışmamasının getireceği olumsuz sonuçlar önümüzdeki dönemlerde yapılacak çalışma ve araştırmalarla ortaya konacaktır (30). 


\section{SONUÇ}

Hemşireler, mesleki eğitimde aldıkları bilgi ve becerileri profesyonel hemşirelik işlevlerini yerine getirmede kullanmaktadır. Hemşireler bireylere ve topluma bütüncül yaklaşırlar. Bunun için birinci basamakta koruyucu bakım olarak KBH'nın farkındalığının artırılması yönündeki çalışmalarda ekibin etkin bir üyesi olarak yer almalıdır. Etkin uygulanan koruyucu bakım hemşireliği ile $\mathrm{KBH}$ prevalansının ve SDBY insidansının düşürülmesi, bireylerin hastalık nedeniyle diyaliz tedavisi alma sürelerinin kısaltılması, merkezde çalışacak insan gücünün ve tedavi maliyetlerinin düşürülmesi, bireylerin evde diyaliz alırken sosyal ve psikolojik olarak desteklenmesi sağlanabilir.

Sağl1k sektöründe yaşanan yeni gelişmeler diyaliz hasta tedavilerinde ve diyaliz merkezlerinde de yaşanmaktadır. Bu gelişmelere paralel olarak diyaliz merkezlerinde önemli görev ve sorum- luluklara sahip diyaliz hemşireleri ön planda olmalıdır. Mart 2019'da çıkarılan yönetmelik ile hemşirelerin sertifikasyon programından çıkarılmıştır. KBH ve diyaliz hastalarının hemşirelik tanıları doğrultusunda bakım almaya gereksinimleri bulunmaktadır. Diyaliz tedavisi öncesi ve sonrası hasta ve yakınlarına hemşireler tarafindan sosyal, psikolojik açıdan desteklenmesi, cilt sorunlar1, ayak bakımı, beslenme, uyku, beden imgesi konusunda sürekli ve düzenli eğitimler verilmelidir. Hemşireler tarafından bakım verilememesi sonucunda hastaların yaşayacağı sorunlar konusunda araştırmalar planlanmalıdır. Araștırma kapsamında; hemşirelik bakım ve girişimlerinin yetersizliğine bağl1 oluşabilecek sorunlar incelenmelidir. Hastaların ve hasta yakınlarının memnuniyeti, yaşam kalitelerinin düzeyi, oluşabilecek komplikasyonların önlenmesi, hastaneye başvuru sıklıklarının artıp artmadığı, eğitim eksikliğine bağlı hasta ve yakınlarının ihtiyaçlarının karşılanıp karşılanmadığı belirlenmelidir.

\section{Kaynaklar}

1. Yiğit V, Erdem R. Türkiye'de Diyaliz Ve Böbrek Transplantasyonu Tedavisinin Maliyet Etkililik Analizi, Mehmet Akif Ersoy Üniversitesi Sosyal Bilimler Enstitüsü Dergisi 2015;7 (13): 182-205.

2. Süleymanlar G, Utaş C, Arınsoy T, Ateş K, Altun B, Altiparmak MR, Serdengeçti K. A Population-Based Survey Of Chronic Renal Disease In Turkey-The CREDIT Study. Nephrology Dialysis, Transplantation: Official Publication Of The European Dialysis And Transplant Association European Renal Association 2011;6 (26):1862-1871.

3. Yiğit V. (2013) Sağlık Hizmetlerinde Ekonomik Değerlendirme: Türkiye'de Diyaliz Ve Böbrek Transplantasyonu Tedavi Yöntemlerinin Maliyet Etkililik Analizi Sosyal Bilimler Enstitüsü Sağlık Yönetimi Anabilim Dalı Sağlık Kurumları Yönetimi Programı Yayımlanmamış Doktora Tezi. Süleyman Demirel Üniversitesi.

4. T.C. Sağlık Bakanlığı Sağlık Hizmetleri Genel Müdürlüğü, Sağlıkta Kalite Standartları: Diyaliz, Eylül 2016, www.kalite.saglik.gov.tr https://dosyamerkez.saglik.gov.tr/Eklenti/6537,sks-diyaliz-kitabipdf.pdf Erişim Tarihi: 15.06.2019.

5. Cinper Ç. (2011) Diyaliz Hemşireleri İşlevlerinin Profesyonel Yaklaşım Yönünden Değerlendirilmesi, Yayımlanmamış Yüksek Lisans Tezi, İstanbul Bilim Üniversitesi Sağlık Bilimleri Enstitüsü Hemşirelik Yüksek Lisans Programı.

6. Kasti J, Pancirova J. Diyaliz İçin Çevresel Rehber Diyalizin Çevresel Yükünü Azaltmak İçin Pratik Bir Kılavuz, European Dialysis and Transplant Nurses Association/ European Renal Care Association (EDTNA/ERCA) Pilatusstrasse 35, CH 6003 Lucerne, Switzerland, 2011, Turkish Edition May 2013.

7. T.C. Sağlık Bakanlığı Türkiye Halk Sağlığı Kurumu, Türkiye Böbrek Hastalıkları Önleme ve Kontrol Programı (20142017) http://sbu.saglik.gov.tr/Ekutuphane/YayinAra?sayfa=4 Erișim Tarihi: 15.06.2019.

8. Birlik H, Akbulut Y. Sağlık Kurumlarında Maliyet Analizi: Diyaliz Merkezinde Bir Uygulama, Legal Mali Hukuk Dergisi 2017;13 (147): 475-492.

9. Karçkay A. (2016) Diyaliz Hemşirelerinin İş Gücü Verimliliğini Etkileyen Faktörler, Yüksek Lisans Bitirme Tezi Okan Üniversitesi Sağlık Bilimler Enstitüsü Sağlık Yönetimi Anabilim Dalı.

10. Kankaya H, Karadakovan A. Obezite Ve Böbrek Hastalıkları, Türk Nefroloji, Diyaliz Ve Transplantasyon Hemşireleri Derneği Nefroloji Hemşireliği Dergisi 2017; 12 (2): 91-96. 
11. Kidney Disease: Improving Global Outcomes (KDIGO) Glomerulonephritis Work Group. KDIGO Clinical Practice Guideline for Glomerulonephritis. Kidney Inter, Suppl. 2012; 2: 139-274. Kidney Disease\&Obesity. http://www.worldkidneyday.org/wp-content/uploads/2017/02/wkd-wof_joint-position.pdf. Erişim Tarihi: 20.04.2019.

12. Arınsoy T. Türkiye'de Hemodiyalizin Bugünü ve Geleceği, Türk Nefroloji Derneği, http://www.nefroloji.org.tr/ pdf/kisokulu2014 Erişim Tarihi: 15.06.2019.

13. Süleymanlar G, Altıparmak MR, Seyahi N, Trabulus S. Türkiye'de Nefroloji, Diyaliz ve Transplantasyon - Registry 2012. Türk Nefroloji Derneği Yayınları, Ankara, 2013.

14. Go AS, Chertow GM, Fan D, et al. Chronic kidney disease and the risks of death, cardiovascular events, and hospitalization. N Engl J Med 2004; 351: 1296-1305.

15. Annual Data Report (USRDS 2013): Atlas of End Stage Renal Disease in the United States. National Institutes of Health, National Institute of Diabetes and Digestive and Kidney Diseases, U. S. Renal Data System, Bethesda, 2013.

16. Kutner NG, Johansen KL, Kaysen GA, et al. The comprehensive dialysis study (CDS): A USRDS special study. Clin J Am Soc Nephrol 2009; 4: 645-50.

17. Türkiye'de Nefroloji, Diyaliz ve Transplantasyon 2013 Raporu, Türk Nefroloji Derneği, http://www.nefroloji.org.tr/ folders/file/registry_kitabi_2014.pdf (Erişim Tarihi: 20.04.2019).

18. Doğan S. (2015) Sürekli Ayaktan Periton Diyalizi Tedavisi Gören Hastalarda Mekanik, Metabolik ve Enfeksiyoz Komplikasyonlar, Uzmanlık Tezi, İnönü Üniversitesi Tıp Fakültesi İç Hastalıkları Anabilim Dalı.

19. Aylaz R, Erci B. Sürekli Ayaktan Periton Diyalizi Hastalarına Evde Verilen Bakımın ve İzlemin Hastaların Öz-Bakım Gücüne ve Diyalize Bağlı Enfeksiyonlardan Korunmalarına Etkisi, İstanbul Üniversitesi Hemşirelik Dergisi 2010;18(1): 40-46.

20. Hemşireler İçin Etik İlke ve Sorumluluklar, Türk Hemşireler Derneği, www.turkhemsirelerdernegi.org.tr Erişim Tarihi: 20.04.2019.

21. Hemşirelik Kanununda Değişiklik Yapılmasına Dair Kanun, TC Sağlık Bakanlığı, 2 Mayıs 2007 tarih ve 5634 Kanun No, www.resmigazete.gov.tr, Erişim Tarihi: 20 Nisan 2019.

22. Hemşirelik Yönetmeliğinde Değişiklik Yapılmasına Dair Yönetmelik, TC Sağlık Bakanlı̆̆ı, 19 Nisan 2011, www.resmigazete.gov.tr, Erişim Tarihi: 20 Nisan 2019.

23. Plantinga LC, Boulware LE, Coresh J, et al. Patient awareness of chronic kidney disease. Trends and Predictors. Arch Intern Med 2008; 168: 2268-75.

24. Nural N. Nefroloji Hemşireliğinde Kanıta Dayalı Uygulamalar, Nefroloji Hemşireliği Dergisi 2015;10 (1):47-52.

25. Wilkınson JM. Pearson Hemşirelik Tanıları Kitabı. 11. Baskı. Ankara: Pelikan Yayınevi; 2018.

26. Kızıltan B, Şendir M. Diyaliz Hastalarında Ağız Bakımının Önemi ve Hemşirenin Rolü, Türk Nefroloji, Diyaliz ve Transplantasyon Hemşireleri Derneği Nefroloji Hemşireliği Dergisi 2018;13(1):9-16.

27. Akça NK. Hemodiyaliz Tedavisi Alan Hastalarda Sık Karşılaşılan Cilt Sorunları ve Hemşirelik Bakımı, Nefroloji Hemşireliği Dergisi 2019;14 (1): 26-32.

28. Akyol A, Özdemir Ş. Koruyucu Ayak Bakım Davranışlarının Ölçülmesinde Yeni Bir Araç: Nottingham Fonksiyonel Ayak Bakım Tanılama Formu- Nottingham Assessment of Functional Footcare (NAFF) Türkçe Geçerlik ve Güvenirlik Çalışması, Nefroloji Hemşireliği Dergisi 2019;14 (1):1-9.

29. Sezen A. Diyaliz Merkezleri Hakkındaki Yönetmeliklerde Değişen İnsan Kaynakları Standartlarının İncelenmesi, Türk Nefroloji, Diyaliz ve Transplantasyon Hemşireleri Derneği Nefroloji Hemşireliği Dergisi 2017;12 (1):43-48.

30. Diyaliz Merkezleri Hakkında Yönetmelik, SB Sağlık Hizmetleri Genel Müdürlüğü, 01 Mart 2019 tarih ve 30701 sayılı Resmi Gazete, www.resmigazete.gov.tr, Erişim Tarihi: 20 Nisan 2019. 